\title{
POSSIBILITIES OF EFFECTIVE PASSIVE VIBRATION ISOLATION OF HYDRAULIC VALVES
}

\author{
Michą Stosiak, Krzysztof Towarnicki \\ Wroctaw University of Science and Technology, Faculty of Mechanical Engineering, Wroctaw, Poland \\ e-mail: michal.stosiak@pwr.edu.pl; krzysztof.towarnicki@pwr.edu.pl
}

\begin{abstract}
The following paper describes the effect of the introduced vibration isolation on the operation of a hydraulic valve. The method of transmitting the external force to the valve control element and examples of vibration sources are presented. The balance of forces acting on the valve spool and the flow intensity in the tested hydraulic system are determined. The assumptions are simplified and discussed in detail. On their basis, numerical simulations have been carried out and verified by experimental tests. The paper ends with brief conclusions.
\end{abstract}

Keywords: passive vibration isolation, vibrations, hydraulic valve, modeling, testing

\section{Introduction}

A specific feature of the operation of hydraulic systems is its dependence on external conditions and the above-mentioned parameters. A working hydraulic element, such as a valve controlling the flow direction or pressure, is constantly subjected to complex forces of various origins, e.g. external vibrations from the ground, pressure pulsation. It is important to be aware that by applying an input to any point in a hydraulic system, it is transferred to components of this system through viscous or elastic elements. The effects of this depend on the place of the input, its amplitude, frequency and physical characteristics of the elements transmitting these forces as well as configuration of this system. An element of the hydraulic system, the main part of which is a control element in the form of a slide, ball, cone, or plate, is subjected to variable loads resulting from changes in operating parameters: the medium flow rate, pressure due to uneven performance of the displacement pump or variable external load. Examples are presented in (Stryczek, 2005). These loads are often stochastic and, in particular cases, they may be harmonic. In general, forces acting on a hydraulic valve can be divided into deliberate and disruptive ones. The group of targeted inputs includes signals that control the operation of valves located in the structure of the control or regulation system. Exemplary values are shown in (Glanowski, 2001; Tomasiak, 2001). A group of excitations disturbing the operation of the valves includes vibrations acting on the valve as described in (Stosiak, 2006). A significant influence of external signals on the operation of modern proportional elements or hydraulic micro-valves should be expected, because the disturbance forces in these elements may have the same magnitude as the control forces. This can lead to many unfavorable effects, e.g. loss of stability, lack of positioning accuracy, damage to seals, increased noise (Cempel, 1989; Pawlaczyk-Łuszczyńska et al., 2001) and excitation and transmission of vibrations through flexible hydraulic pipes with non-linear characteristics (Bogdevičius et al., 2021). A strong trend in the development of the proportional control technology can be noted in various types of hydraulic elements was confirmed by the examples in (Osiecki, 1998; Addison et al., 2017; Pizon, 1995; Tomasiak, 2001a,b), which have been replacing the conventional elements used so far, thus providing new possibilities in terms 
of the response time to the control signal and frequency bands (Kudźma et al., 2014) as well as entirely new opportunities with respect to the implementation of programmed work cycles, reduction of dynamic surpluses or mitigation of transient states.

Most generally, the complex problem of vibration transmission by a machine or device can be divided into three basic, interrelated stages:

- sources of vibrations,

- vibration transmission paths,

- vibration effects.

Propulsion systems, such as an internal combustion engine, which performs a periodic, variable duty cycle, are important sources of vibrations. A working hydraulic system is also a source of mechanical vibrations caused mainly by pressure shock changes and the periodic operating principle of a displacement pump (Kollek et al., 2014). The vibrations generated in this way are characterized by different frequencies, so their transmission paths are different (Fiebig and Wróbel, 2017).

\section{Reduction of the influence of external mechanical vibrations on a hydraulic valve}

The introduction of a material with elastic dissipative properties suitable for reduction of transmitted amplitudes and the frequency range of vibrations should reduce the vibration amplitudes of the valve control elements. A case was analyzed in which in order to extend the frequency range of effective vibration isolation, a hydraulic distributor was mounted in a special holder and supported on both sides by springs with known characteristics. The spring packs were installed between the distributor body and the handle - as shown in Fig. 1. Effective vibration isolation is that for which the ratio of the vibration acceleration amplitude of the distributor body to the amplitude of forced vibration acceleration is lower than one.

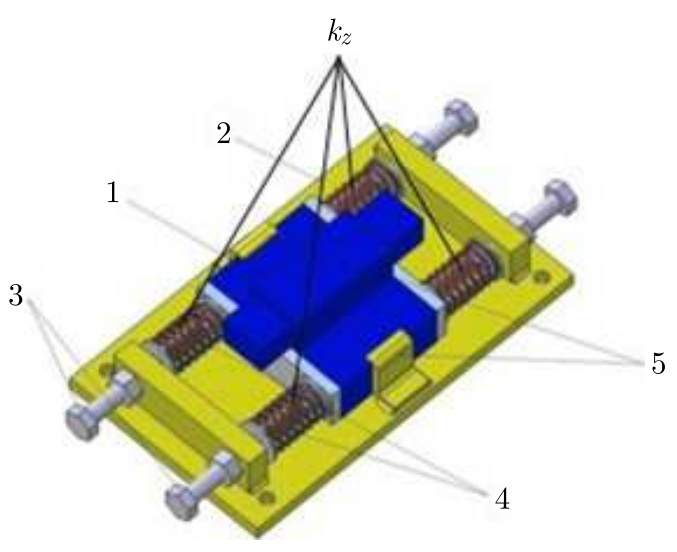

Fig. 1. Handle of the second valve: 1 - hydraulic valve (distributor), 2 - handle base, 3 - spring pre-deflection screws, 4 - springs, 5 - securing catches

The handle design shows that the valve mounted in it is tied with springs of the equivalent stiffness $k_{z}$, sliding along the handle base (Fig. 1) and rubbing against it according to the dry friction model. The valve is supported by the springs on both sides. The diagram of the hydraulic system used with the distributor is shown in Fig. 2 (the periodic kinematic excitation is described with a harmonic function), 


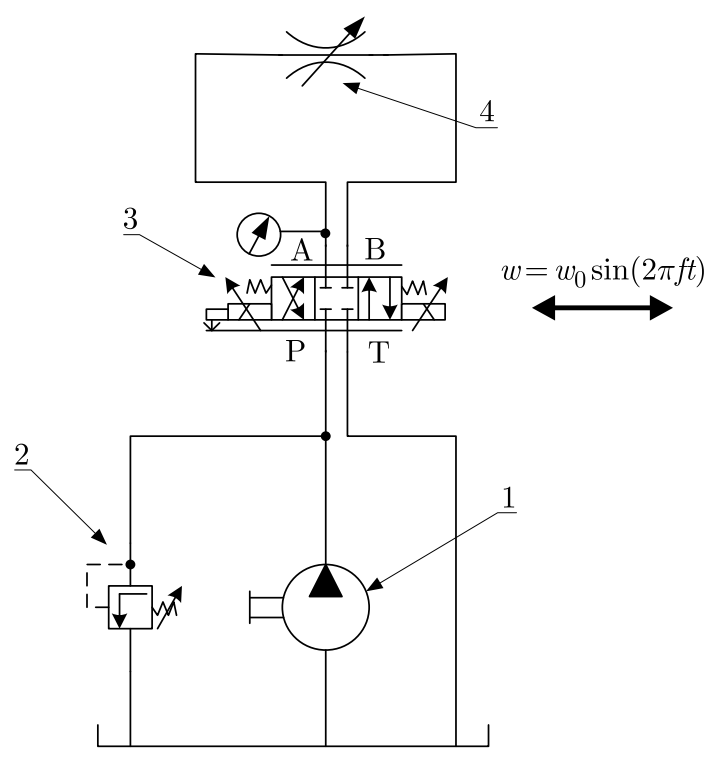

Fig. 2. Hydraulic diagram of the tested element system: 1 - feed pump, 2 - maximum valve, 3 - tested element (proportional valve 4WRE 6 E08-12/24Z4/M), 4 - adjustable throttle valve

For a two-mass system, the model of a proportional valve operating in the hydraulic system shown in Fig. 3 is presented as a system of four equations

$$
\begin{aligned}
& m_{1} \ddot{x}_{s u}+\pi d_{t} \frac{l}{h} \mu\left(\dot{x}_{s u}-\dot{x}_{k 0}\right)+0.72 \frac{1}{\sqrt{\xi}} 2 s_{s} \frac{\left(x_{s u}-x_{p}\right)^{2}}{x_{m}}\left(p_{1}-p_{2}\right)+k_{s z}\left(x_{s u}-x_{k 0}\right)=F_{M} \\
& Q_{p}-\frac{3}{2} s_{s} \frac{\left(x_{s u}-x_{p}\right)^{2}}{x_{m}} \sqrt{\frac{2}{\rho}\left(p_{1}-p_{2}\right)}-a_{p 1} p_{1}-k_{k 1} \dot{p}_{1}=0 \\
& Q_{p}-a_{p 1} p_{1}-k_{k 1} \dot{p}_{1}-k_{k 2} \dot{p}_{2}-C_{q 1} A_{a} \sqrt{\frac{2 p_{2}}{\rho}}=0 \\
& m_{2} \ddot{x}_{k 0}+k_{s z}\left(x_{k 0}-x_{s u}\right)+c_{s 1}\left(\dot{x}_{k 0}-\dot{x}_{s u}\right)+k_{z}\left(x_{0 s}+x_{k 0}-w\right) \\
& \quad+m_{2} \mu_{2} g\left[1-H\left(l_{0}-\left|x_{k 0}-w\right|\right)\right] \operatorname{sgn}\left(\dot{x}_{k 0}-\dot{w}\right)+\operatorname{sgn}\left(\dot{x}_{k 0}-\dot{w}\right) m_{2} \mu_{i} g=0
\end{aligned}
$$

where $g$ is standard gravity $\left[\mathrm{m} / \mathrm{s}^{2}\right], H-$ is the Heaviside function $[-], c_{s 1}-$ is damping in the slider-sleeve pair $[\mathrm{Ns} / \mathrm{m}], p_{1}$ - is pressure upstream of the distributor $[\mathrm{Pa}], p_{2}-$ is pressure downstream of the distributor $[\mathrm{Pa}], s_{s}$ - is the maximum gap width $[\mathrm{m}], w-$ is the vibration amplitude of the excitation $[\mathrm{m}], x_{m}$ - is gap length [m], $x_{p}$ - is mutual displacement of the spool and body edges $[\mathrm{m}], x_{0 s}$ - is pre-deflection of springs $[\mathrm{m}], x_{s u}$ - is piston spool displacement $[\mathrm{m}]$, $x_{k 0}$ - is distributor body displacement $[\mathrm{m}], F_{M}$ - force that comes from the controls $[\mathrm{N}], k_{s z}-$ stiffness is replaced by the springs securing the slider $[\mathrm{N} / \mathrm{m}]$.

The first equation describes the balance of forces acting on the slider setting in motion the vibrating body, which is associated with the centering springs and friction in the slider pair. The second and third equations describe the balance of the flow rate in the hydraulic system operating without the maximum valve. The fourth equation describes the forces acting on the valve body in the case under study. It was assumed that after the $l_{0}$ clearance is removed, the valve body rubs against the securing catches. Model (2.1) was built with the simplifying assumptions that:

- the working fluid does not change its properties,

- Coulomb friction in the slide pair is ignored,

- cooperation between the valve body and the handle represents Coulomb friction, 


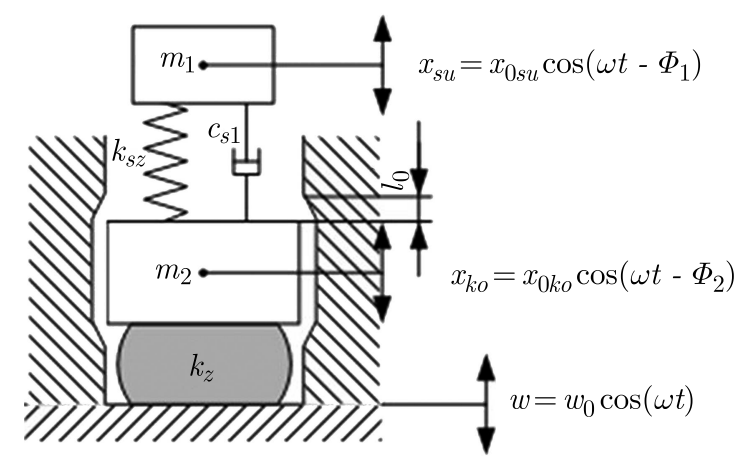

Fig. 3. The "black box" method in valve vibration

- after the clearance is removed, the cooperation between the valve body and securing handles represents Coulomb friction,

- spring characteristics are linear and described by the stiffness $k$,

- the description of the hydraulic system is based on a model with concentrated parameters,

- the model does not take into account the influence of pipes on valve vibration.

The list of the most important symbols in the system of equations (2.1) is presented in Table 1.

Table 1. List of the most important symbols with values

\begin{tabular}{|l|c|c|c|}
\hline \multicolumn{1}{|c|}{ Parameter } & Symbol & Value & SI unit \\
\hline \hline Leakage coefficient & $a_{p l}$ & $2.5 \cdot 10^{-11}$ & $\mathrm{~m}^{4} \mathrm{~s} / \mathrm{kg}$ \\
\hline Area of the throttle valve gap & $A_{a}$ & $1.5 \cdot 10^{-6}$ & $\mathrm{~m}^{2}$ \\
\hline $\begin{array}{l}\text { Equivalent stiffness of the spool centering } \\
\text { springs }\end{array}$ & $k_{1}$ & 4884 & $\mathrm{~N} / \mathrm{m}$ \\
\hline Equivalent stiffness of the securing springs & $k_{z}$ & 86000 & $\mathrm{~N} / \mathrm{m}$ \\
\hline Capacitance & $c_{k l}$ & $0.62 \cdot 10^{-12}$ & $\mathrm{~m}^{5} / \mathrm{N}$ \\
\hline Throttle valve flow rate & $C_{q l}$ & 0.6 & - \\
\hline Piston diameter & $d_{t}$ & $12 \cdot 10^{-3}$ & $\mathrm{~m}$ \\
\hline Spool-sleeve pair gap thickness & $h$ & $1.5 \cdot 10^{-7}$ & $\mathrm{~m}$ \\
\hline Piston length & $l$ & $36.6 \cdot 10^{-3}$ & $\mathrm{~m}$ \\
\hline $\begin{array}{l}\text { Gap between the valve body and the } \\
\text { securing catches }\end{array}$ & $l_{0}$ & $0.2 \cdot 10^{-3}$ & $\mathrm{~m}$ \\
\hline Piston spool weight and 1/3 of spring weight & $m_{1}$ & 0.0344 & $\mathrm{~kg}$ \\
\hline Distributor body weight & $m_{2}$ & 4.5 & $\mathrm{~kg}$ \\
\hline Pressure in the fill line & $p_{z}$ & 0 & $\mathrm{~Pa}$ \\
\hline Calculated pump capacity & $Q_{p}$ & $1 \cdot 10^{-4}$ & $\mathrm{~m}{ }^{3} / \mathrm{s}$ \\
\hline $\begin{array}{l}\text { Friction coefficient of the valve body } \\
\text { against the securing catches }\end{array}$ & $\mu_{2}$ & 0.1 & - \\
\hline $\begin{array}{l}\text { Friction coefficient of the valve body } \\
\text { against the catch base }\end{array}$ & $\mu_{i}$ & 0.12 & - \\
\hline Service fluid density & $\rho$ & 900 & $\mathrm{~kg} / \mathrm{m}^{3}$ \\
\hline Fluid dynamic viscosity & $\mu$ & 0.22 & $\mathrm{Ns} / \mathrm{m}$ \\
\hline Local loss coefficient & $\xi$ & 1.78 & - \\
\hline
\end{tabular}

The solution of model (2.1) for the equivalent stiffness $k_{z}=86000 \mathrm{~N} / \mathrm{m}$ is presented in Fig. 4 as the ratio of the amplitude of vibration acceleration of the proportional distributor 
body $a_{2}$ to the amplitude of forced vibration acceleration $a_{0}$, known as the "transfer function". The kinematic external excitation is described as a harmonic function $\left.w(t)=w_{(} 0(f)\right) \sin (2 \pi f t)$, where $w_{0}(f)$ is the amplitude $[\mathrm{m}]$ of the excitation corresponding to the frequency of the excitation, $f$ is the frequency of the kinematic excitation $[\mathrm{Hz}]$ and $t$ is time $[\mathrm{s}]$. As for the frequency $f=10 \mathrm{~Hz}$, the amplitude is $w_{0}(10)=3.76 \cdot 10^{-3} \mathrm{~m}$ for $f=15 \mathrm{~Hz}, w_{0}(15)=2.25 \cdot 10^{-3} \mathrm{~m}$; for $f=20 \mathrm{~Hz}, w_{0}(20)=1.33 \cdot 10^{-3} \mathrm{~m}$; for $f=25 \mathrm{~Hz}, w_{0}(25)=0.84 \cdot 10^{-3} \mathrm{~m}$; for $f=30 \mathrm{~Hz}, w_{0}(30)=$ $0.48 \cdot 10^{-3} \mathrm{~m}$; for $f=35 \mathrm{~Hz}, w_{0}(35)=0.41 \cdot 10^{-3} \mathrm{~m}$; for $f=40 \mathrm{~Hz}, w_{0}(40)=0.37 \cdot 10^{-3} \mathrm{~m}$; for $f=45 \mathrm{~Hz}, w_{0}(45)=0.27 \cdot 10^{-3} \mathrm{~m}$; for $f=50 \mathrm{~Hz}, w_{0}(50)=0.21 \cdot 10^{-3} \mathrm{~m}$; for $f=55 \mathrm{~Hz}$, $w_{0}(55)=0.15 \cdot 10^{-3} \mathrm{~m}$; for $f=60 \mathrm{~Hz}, w_{0}(60)=0.052 \cdot 10^{-3} \mathrm{~m}$.

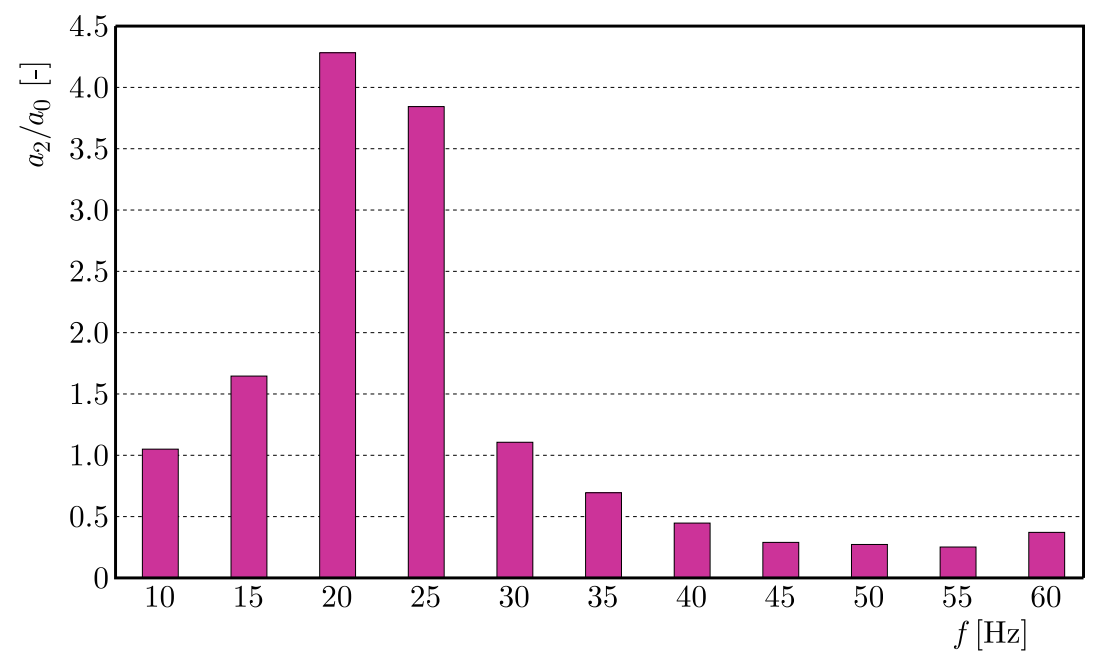

Fig. 4. The vibration acceleration amplitude of the proportional distributor body $a_{2}$ as a function of the vibration acceleration amplitude $a_{0}$ for $f$ from 10 to $60 \mathrm{~Hz}$

The analysis of the simulation results shows a significant increase of the body vibrations amplitude at a frequency of about $20 \mathrm{~Hz}$. This is caused by the occurrence of resonance as the mass of the vibrating valve is about $4.5 \mathrm{~kg}$, while the equivalent spring stiffness of the handle is $k_{z}=86000 \mathrm{~N} / \mathrm{m}$, which means that the resonance occurs at a frequency of approximately $22 \mathrm{~Hz}$. Thus, in the range of $10-30 \mathrm{~Hz}$, an increase in the amplitude of acceleration of the distributor body is observed - vibration ineffective.

\section{Searching for effective vibration isolation solutions}

The goal was to propose such isolation of the valve that will widen the insulation zone and reduce the resonance zone. The "black box" method was used for this problem as shown in Fig. 5.

If a material with linear characteristics of stiffness $k_{z}$ and damping $c_{2}$ described as

$$
k_{z}\left(x_{k 0}-w\right)+c_{2}\left(\dot{x}_{k 0}-\dot{w}\right)^{2}
$$

is introduced between the valve body and the vibrating holder, and assuming that the clearance $l_{0}$ is not removed, the fourth equation in the system of equations (2.1) can have the following form

$$
\begin{aligned}
& m_{2} \ddot{x}_{k 0}+k_{s z}\left(x_{k 0}-x_{s u}\right)+c_{s 1}\left(\dot{x}_{k 0}-\dot{x}_{s u}\right)+k_{z}\left(x_{0 s}+x_{k 0}-w\right)+c_{2}\left(\dot{x}_{k 0}-\dot{w}\right) \\
& \quad+\operatorname{sgn}\left(\dot{x}_{k 0}-\dot{w}\right) m_{2} \mu_{i} g=0
\end{aligned}
$$

After the parameters assume the values of $k_{z}=20000 \mathrm{~N} / \mathrm{m}$ and $c_{2}=50 \mathrm{Ns} / \mathrm{m}$ and then $c_{2}=250 \mathrm{Ns} / \mathrm{m}$, it is possible to assess the influence of the damping change on the effectiveness 


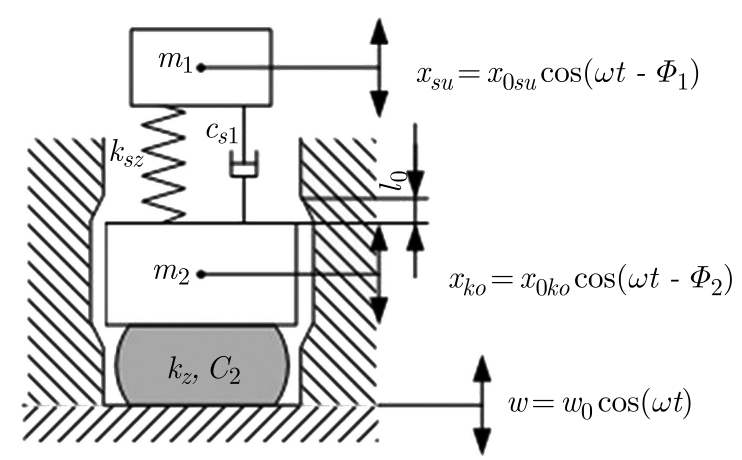

Fig. 5. The "black box" method in valve vibration isolation

of the valve body isolation from the vibrating ground. Similarly, the influence of the stiffness change on the effectiveness of isolating the valve body from the vibrating ground can be assessed by using $k_{z}=120000 \mathrm{~N} / \mathrm{m}$. Figure 6 shows the values of the "transfer function" understood as the ratio of the amplitude of acceleration of the valve body vibrations $a_{2}$ to the amplitude of acceleration of the forced vibration $a_{0}$ for different damping values $c_{2}$.

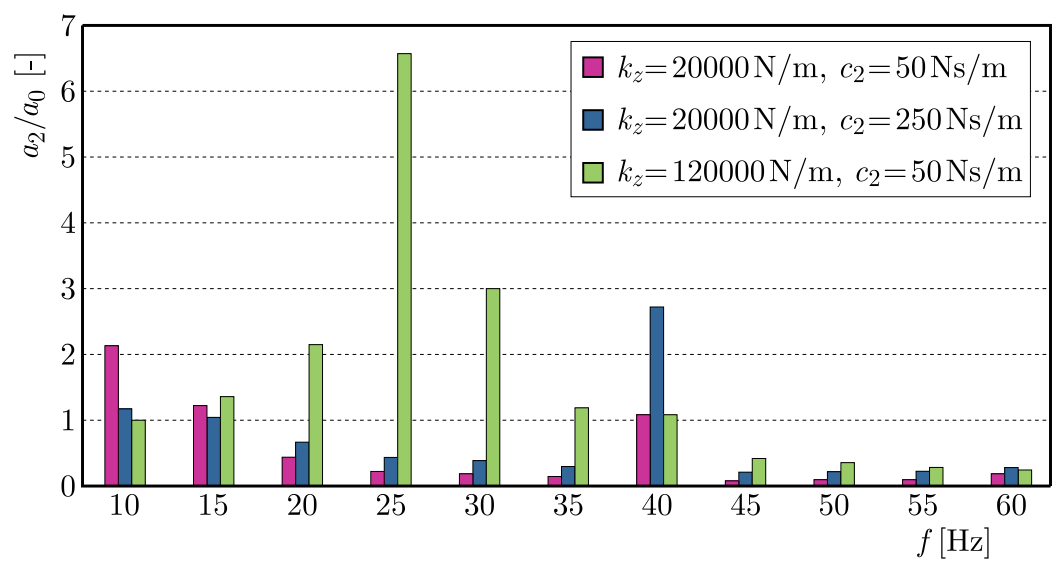

Fig. 6. The vibration acceleration amplitude of the proportional distributor body $a_{2}$ related to the amplitude of forced vibration acceleration $a_{0}$ for $f$ from 10 to $60 \mathrm{~Hz}$

The analysis of Figs. 4 and 6 shows that by using a vibration isolator with linear characteristics and different values of the $k_{z}$ and $c_{2}$ parameters, it is possible to limit the range of the resonance area and increase the range of isolation, i.e. the area for the ratio $a_{2} / a_{0}<1$. Further improvement of the isolation efficiency of the valve body from the vibrating substrate can be sought by using insulators with non-linear characteristics.

If a material with nonlinear stiffness $k_{z}\left(x_{k 0}-w\right)^{2}$ and damping proportional to the relative velocity $c_{2}\left(\dot{x}_{k 0}-\dot{w}\right)$ is inserted between the valve body and the vibrating base, and assuming that the clearance $l_{0}$ is not removed, the fourth equation in the system of equations (2.1) can take the following form

$$
\begin{aligned}
& m_{2} \ddot{x}_{k 0}+k_{s z}\left(x_{k 0}-x_{s u}\right)+c_{s 1}\left(\dot{x}_{k 0}-\dot{x}_{s u}\right)+k_{z}\left(x_{0 s}+x_{k 0}-w\right)^{2}+c_{2}\left(\dot{x}_{k 0}-\dot{w}\right) \\
& \quad+\operatorname{sgn}\left(\dot{x}_{k 0}-\dot{w}\right) m_{2} \mu_{i} g=0
\end{aligned}
$$

By supplementing the set of parameters with $k_{z}=20000 \mathrm{~N} / \mathrm{m}$ and $c_{2}=50 \mathrm{Ns} / \mathrm{m}$ or, for example, in order to calculate the share of damping in the process of reducing the vibrations of the valve body $c_{2}=250 \mathrm{Ns} / \mathrm{m}$, we can obtain a numerical solution representing the vibrations of the valve. Figure 7 presents the values of the "transfer function" understood as the ratio of the 
amplitude of acceleration of the valve body vibrations $a_{2}$ to the amplitude of forced vibration acceleration $a_{0}$.

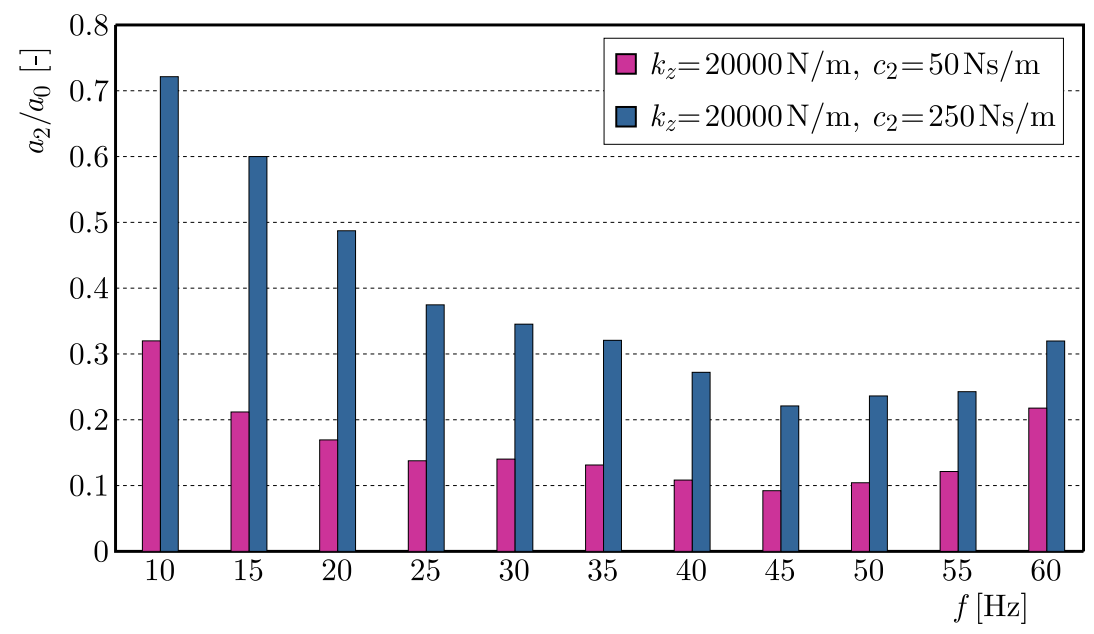

Fig. 7. The vibration acceleration amplitude of the proportional distributor body $a_{2}$ as a function of the amplitude of forced vibration acceleration $a_{0}$ for $f$ from 10 to $60 \mathrm{~Hz}$

In this case, it is also observed that for a given stiffness, an increase in the damping value causes an increase in the value of the "transfer function" understood as the ratio of $a_{2}$ to $a_{0}$. However, unlike the case where the material with linear stiffness and damping characteristics is used, here the value of the "transfer function" is less than one over the entire given frequency range.

If a vibration damper with nonlinear damping and linear stiffness $\left(k_{z}=20000 \mathrm{~N} / \mathrm{m}\right)$ $k_{z}\left(x_{k 0}-w\right)+c_{2}\left(\dot{x}_{k 0}-\dot{w}\right)^{2}$ is used to isolate vibrations from the base, the ratio of the vibration amplitude of the distributor body $a_{2}$ to the vibration amplitude of the base $a_{0}$ for selected excitation frequencies is as shown in Fig. 8.

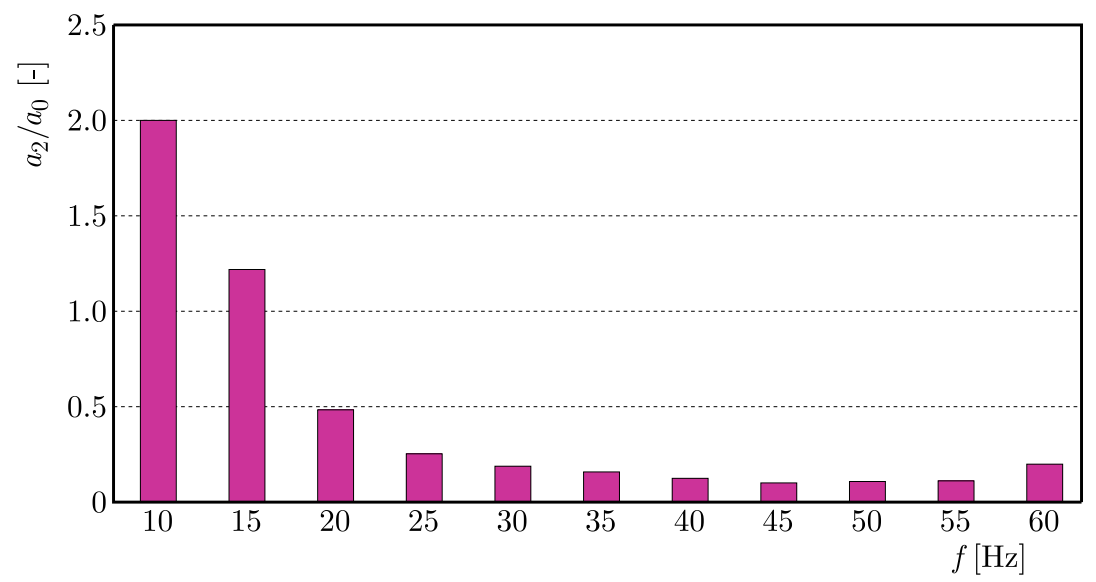

Fig. 8. The vibration acceleration amplitude of the proportional distributor body $a_{2}$ as a function of the amplitude of forced vibration acceleration $a_{0}$ for $f$ from 10 to $60 \mathrm{~Hz}$

Also a widening of the effective range of vibration isolation is observed for such an isolator model. Additionally, the spool frequency of a typical single-stage spool distributor is particularly revelant in this area. 


\section{Experimental verification of the possibility of reducing vibrations of a hydraulic valve by means of spring packs}

In order to verify the conclusions resulting from theoretical discussion and from simulation models and to test technical feasibility of the proposed solutions, experimental tests were carried out. The Mannesmann-Rexroth 4WRE 6 E08-12/24Z4/M proportional distributor was mounted in a special holder II (Fig. 2), as shown in the photo in Fig. 9. The proportional valve was placed in the special holder II (Fig. 2) and supported on both sides by springs so that there were two springs connected in parallel on each side of the valve. This parallel arrangement of the springs had the equivalent stiffness of $k_{z}=86000 \mathrm{~N} / \mathrm{m}$, and the initial deflection was set at $2 \mathrm{~mm}$. The summary results are presented in Fig. 10.

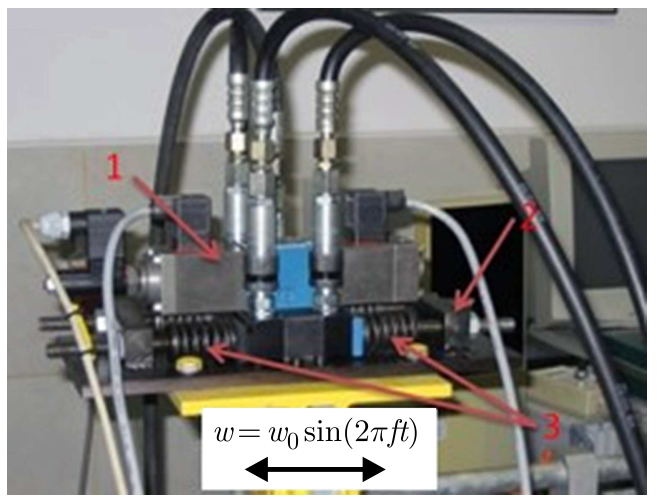

Fig. 9. Proportional distributor mounted in special holder II during experimental tests and supported on both sides by springs: 1 - hydraulic distributor, 2 - vibrating special holder II, 3 - set of four springs

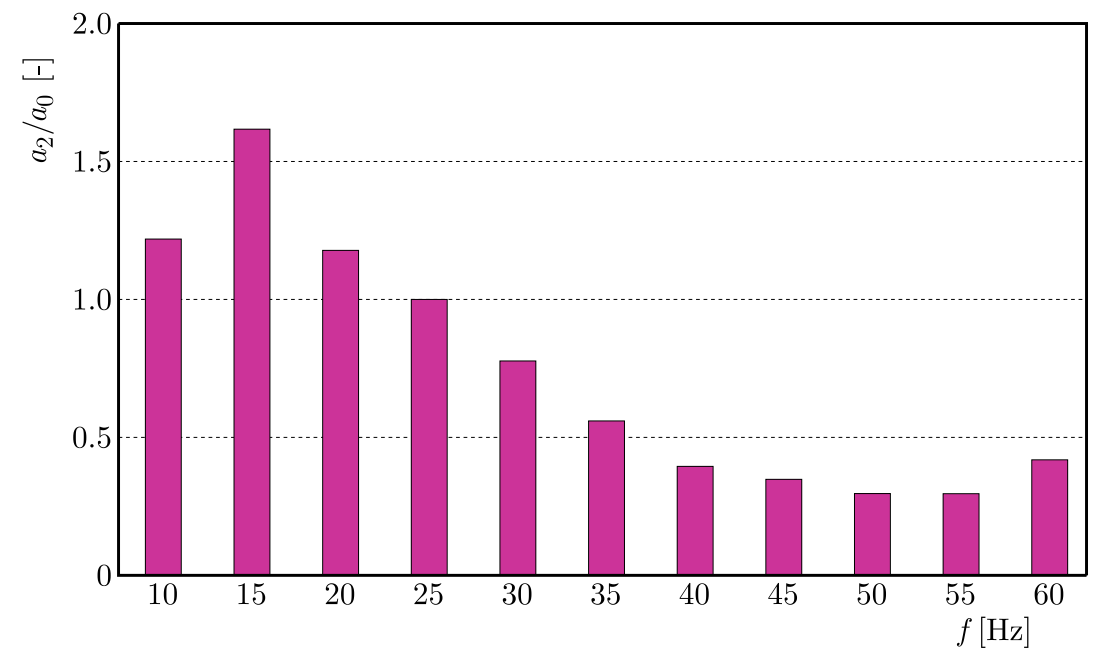

Fig. 10. The vibration acceleration amplitude of the proportional distributor body $a_{2}$ as a function the amplitude of forced vibration acceleration $a_{0}$ for $f$ from 10 to $60 \mathrm{~Hz}$

The applied set of springs and the handle reduced the amplitudes of accelerating vibrations of the valve body in the frequency range of $25-60 \mathrm{~Hz}$.

\section{Application of analytical approximate methods to the analysis of nonlinear valve vibration reduction systems}

In engineering practice, the analysis of vibrating systems is often based on consideration of linear systems. However, more detailed and accurate results can be obtained by taking into account 
non-linearities that sometimes occur. This way the effect of nonlinearities on the behavior of the system can also be assessed. In mechanical systems, elastic or damping elements may be the sources of nonlinearity. In some cases, mass of a system is variable. Damping may be proportional not only to the velocity of the first power but also to the square of it $v^{2}$. Also, the spring rate constant can change with deflection of the spring.

In the vast of rich specialist literature, only a few authors (Balachandran and Magrab, 2009; Kulisiewicz et al., 2001; Bocian and Kulisiewicz, 2014; Harris and Piersol, 2002; Ibrachim, 2008; MacDuff and Curreri, 1960; Gao et al., 2021; Guo et al., 2019; Bocian, 2019) present a broad analysis of vibrations of nonlinear systems. Therefore in this Section, using the reasoning described extensively in the mentioned literature, we will present a selected model with either non-linear damping or non-linear springs.

An important feature of the system related to nonlinearity of the spring is the variaton of natural frequency with the amplitude. This differs from systems with nonlinear damping, where changes in the natural frequency due to damping changes are very small. In systems with nonlinear springs, even a slight change in the amplitude may cause significant changes in the value of the natural frequency. In systems with non-linear springs, there are also harmonic and sub-harmonic deflection components. When analyzing a vibrating system with nonlinear springs, we can obtain harmonic components of motion with values greater or lower than the frequency of the excitation force.

Schwesinger's method (MacDuff and Curreri, 1960) is useful for analyzing vibrating systems with nonlinearities. It is an approximate method based on a one-member approximation that allows us to consider vibrations of systems with variable mass, non-linear spring or non-linear damping.

In this method, the vibration is assumed to be harmonic, and the displacement can be described by the following function

$$
x(t)=x_{0} \sin (\omega t)
$$

This assumption is responsible for inaccuracy within this method, because only one harmonic is considered, without harmonics of higher orders. The starting point is to construct a differential equation of forces acting on a body with mass $m$. The author of the method introduces the notion of an equivalent force as a disturbing force acting on mass $m$. This force would be equal to zero for a linear system if the assumption of simple harmonic motion was true. For a nonlinear system, there are still harmonics of higher orders in the system response, so, in general, the displacement should be described as follows

$$
x(t)=x_{0} \sin (\omega t)+x_{02} \sin (2 \omega t)+x_{03} \sin (3 \omega t)+\cdots+x_{0 n} \sin (n \omega t)
$$

where $\omega$ is the angular frequency $[\mathrm{rad} / \mathrm{s}]$.

By applying only the first term in the sum given by Eq. (5.2), the existing forces caused by the harmonics of higher orders are ignored. The harmonics of higher orders acting on the mass combine into one force, expressed as the equivalent force. Schwesinger's method seeks the minimum of the integral that he defines from the square of the equivalent force that he introduces, takes the value of the amplitude $x_{0}$ and identifies the force that must satisfy the condition for the integral to reach the minimum. The following values of the force components $F_{1}$ and $F_{2}$ are obtained

$$
\begin{aligned}
& F_{1}=\frac{1}{\pi} \int_{0}^{2 \pi}\left[F(x)-m \omega^{2} x_{0} \sin (\omega t)+\frac{d m}{d x} \omega^{2} x_{0}^{2} \cos ^{2}(\omega t)\right] \sin (\omega t) d(\omega t) \\
& F_{2}=\frac{1}{\pi} \int_{0}^{2 \pi} F(\dot{x}) \cos (\omega t) d(\omega t)
\end{aligned}
$$


whereas the overall force is expressed in the equation

$$
F^{2}=F_{1}^{2}+F_{2}^{2}
$$

and the phase shift is described with the equation

$$
\Phi=\arctan \frac{F_{2}}{F_{1}}
$$

After the transformations based on equation (5.4), the characteristic equation is obtained, from which - after assuming the vibration amplitude values - we can calculate the corresponding frequencies. In this way, we obtain a curve showing characteristic steady-state vibrations of the body with mass $m$ supported by a system of springs with nonlinear characteristics.

The method is described in detail by MacDuff and Curreri (1960) and others, so here we only outline its main ideas and reasoning.

By using this method, it is possible to evaluate the effect of a nonlinear system on vibration reduction of a distributor body excited by a harmonic force. If it is assumed that the nonlinear stiffness of the isolating component is expressed with the equation

$$
F(x)=k_{1} x+k_{3} x^{3}
$$

where $k_{1}$ and $k_{3}$ are the constants of the spring in $[\mathrm{N} / \mathrm{m}]$ and $\left[\mathrm{N} / \mathrm{m}^{3}\right]$, respectively, and the damping is proportional to the velocity

$$
F(\dot{x})=c \dot{x}
$$

where $c$ is the damping constant in $[\mathrm{kg} / \mathrm{s}]$, then equations (5.3) can be written as follows

$$
\begin{aligned}
& F_{1}=\frac{1}{\pi} \int_{0}^{2 \pi}\left[c_{1} x_{0} \sin (\omega t)+c_{3} x_{0}^{3} \sin ^{3}(\omega t)-m x_{0} \omega^{2} \sin (\omega t)\right] \sin (\omega t) d(\omega t) \\
& F_{2}=\frac{1}{\pi} \int_{0}^{2 \pi} k x_{0} \omega \cos ^{2}(\omega t) d(\omega t)
\end{aligned}
$$

Applying Schwesinger's method and assuming the system parameters $m=4.5 \mathrm{~kg}$, $k_{1}=86000 \mathrm{~N} / \mathrm{m}, k_{3}=8600000 \mathrm{~N} / \mathrm{m}^{3}$, the amplitude of the harmonic excitation force of $F_{0}=90 \mathrm{~N}$, and $c_{1}=80 \mathrm{~kg} / \mathrm{s}$, we can obtain the characteristic equation of steady-state vibrations of the valve body. For the assumed value of the vibration amplitude, the frequency values are calculated according to the above method and are given in Table 2 .

Figure 11 shows the steady-state vibration amplitude of a nonlinear vibration isolation system and, for comparison, a linear system with $k=86000 \mathrm{~N} / \mathrm{m}$ and $c=160 \mathrm{~kg} / \mathrm{s}$ parameters. The steady-state vibration amplitude for a linear system can be calculated from the following equation (Goliński, 1979)

$$
x_{0}=\frac{F_{0}}{k} \frac{1}{\sqrt{\left[1-\left(\frac{\omega}{\omega_{0}}\right)^{2}\right]^{2}+\left(\frac{c \omega}{m \omega_{0}^{2}}\right)^{2}}}
$$

As we can see, the damping limits the amplitude in the non-linear system, but its values are much higher than in the linear system. The diagram in Fig. 11 shows that in the nonlinear model (with nonlinear stiffness), for a given harmonic excitation with a constant amplitude (force) and with a change in the excitation frequency (deviation from resonance), there is a sharp decrease 
Table 2. Steady-state vibration amplitudes in the nonlinear system and frequencies calculated according to Schwesinger's method

\begin{tabular}{|c|c|c|}
\hline$x_{0}[\mathrm{~m}]$ & $f_{1}[\mathrm{~Hz}]$ & $f_{2}[\mathrm{~Hz}]$ \\
\hline \hline 0.0081 & 21.93 & 22 \\
\hline 0.0078 & 21.54 & 22.38 \\
\hline 0.007 & 21.01 & 22.78 \\
\hline 0.006 & 20.6 & 23.20 \\
\hline 0.005 & 20.25 & 23.68 \\
\hline 0.004 & 19.24 & 24.31 \\
\hline 0.003 & 17.98 & 25.25 \\
\hline 0.002 & 15.32 & 26.94 \\
\hline 0.0015 & 12.17 & 28.5 \\
\hline 0.0011 & 4.88 & 30.6 \\
\hline
\end{tabular}

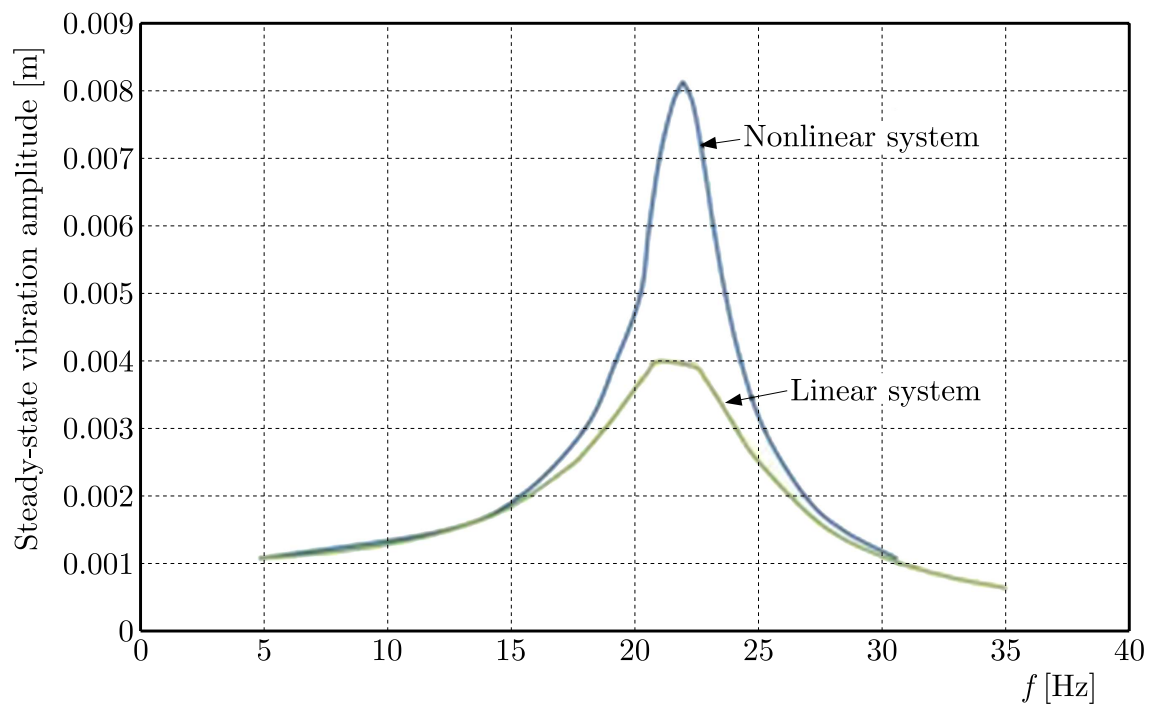

Fig. 11. Steady-state vibration amplitude of the system with the nonlinear stiffness characteristic and linear damping, and vibration amplitude of the system with the linear stiffness characteristic and linear damping

in the amplitude of steady vibrations, e.g. of the valve body, which is much higher than in the linear model.

Another interesting and applicable method is the concept of viscous damping replacement. The analysis of systems with nonlinear damping and linear stiffness can be carried out using the method based on this concept. In this method, losses caused by dry friction, damping proportional to $v^{2}$ and other forms of damping are replaced by the so-called equivalent viscous damping, which has the same effect on the behavior of the system (Harris and Piersol, 2002; MacDuff and Curreri, 1960). Hence this method leads to linearization of the equation describing the system, because it converts the nonlinear differential equation into a linear one. This method assumes that the body is acted on by a harmonic force.

If it is assumed that the resistance in the damper can be described by

$$
F(\dot{y})=c \dot{y}=-y_{0} c \omega \sin (\omega t)
$$

where $\dot{y}$ is the time derivative of the relative displacement $y=y_{0} \cos (\omega t)$, then we can calculate the work of the force per period 


$$
W_{T}=c y_{0}^{2} \omega \int_{0}^{2 \pi} \sin ^{2}(\omega t) d(\omega t)=c y_{0}^{2} \omega \pi
$$

where $W_{T}$ is the work per period.

Moreover, the general formula for work per period can be presented as (MacDuff and Curreri, 1960)

$$
W_{T}=\int_{0}^{2 \pi} F(\dot{y}) \dot{y} d t
$$

The equivalent damping coefficient $C_{e q}$ in a non-viscous damper is obtained by comparing expressions (5.11) and (5.12)

$$
C_{e q}=\frac{1}{y_{0}^{2} \omega \pi} \int_{0}^{2 \pi} F(\dot{y}) \dot{y} d t
$$

This is an approximation method and has limited applicability, because among others, the motion is assumed to be harmonic. It can be used in cases where damping is not large enough to cause distortion of the motion sinusoid. However, using this method and bearing in mind its limitations can lead to generalization that for many types of nonlinear dampings the curve characterizing the steady-state vibration amplitude has a smoother course (MacDuff and Curreri, 1960). This is also true for a vibration system with one degree of freedom for a linear spring connected in parallel and damping that is proportional to the square of velocity. Assuming that the vibrating mass $m$ is connected to the vibrating base by a linear spring with stiffness $c$ and a damper whose resistance can be written as

$$
F(\dot{y})=\lambda \dot{y}^{2}
$$

where $\lambda$ is a constant, and $\dot{y}$ is the relative velocity, after writing the relative displacement of mass $m$ as

$$
y=y_{0} \cos (\omega t)
$$

the work per one period can be calculated for the damper, whose resistance is given by equation $(5.13)$

$$
W_{T}=2.66 \omega^{2} y_{0}^{3} \lambda
$$

By comparing the work per period for damping proportional to the square of relative velocity with equation (5.11), the equivalent damping coefficient is obtained

$$
C_{e q}=0.8488 y_{0} \omega \lambda
$$

Then, substituting the calculated form of the equivalent damping coefficient for the known form of the dimensionless damping coefficient $\gamma$ yields

$$
\gamma=\frac{k_{e q}}{2 m \omega_{0}}=0.4244 y_{0} B \frac{\omega}{\omega_{0}}
$$

where $B=\lambda / m$. 
The equation for the coefficient $\gamma$ is incorporated into the equation describing motion of a system with one degree of freedom, linear stiffness and viscous damping

$$
\frac{y_{0}}{w_{0}}=\frac{\left(\frac{\omega}{\omega_{0}}\right)^{2}}{\sqrt{\left(1-\frac{\omega^{2}}{\omega_{0}^{2}}\right)^{2}+\left(2 \gamma \frac{\omega}{\omega_{0}}\right)^{2}}}
$$

thus yielding the equation

$$
\frac{y_{0}}{w_{0}}=\frac{\left(\frac{\omega}{\omega_{0}}\right)^{2}}{\sqrt{\left(1-\frac{\omega^{2}}{\omega_{0}^{2}}\right)^{2}+0.72\left(y_{0} B \frac{\omega^{2}}{\omega_{0}^{2}}\right)^{2}}}
$$

The substitution $z=y_{0}^{2}$ can lead to the form shown below

$$
0.72 B^{2}\left(\frac{\omega}{\omega_{0}}\right)^{4} z^{2}+\left[1-\left(\frac{\omega}{\omega_{0}}\right)^{2}\right]^{2} z-\left(\frac{\omega}{\omega_{0}}\right)^{4} w_{0}^{2}=0
$$

By solving the above equation with respect to $y_{0}$ and parameterizing it, we can obtain the final form of the relationship between the relative vibration amplitude and the frequency ratio. Detailed solutions are given in (MacDuff and Curreri, 1960) and others. The roots of Eq. (5.21), assuming a positive discriminant, are the numbers $z_{1}$ and $z_{2}$, satisfying the equations

$$
z_{1,2}=-\frac{0.694}{B^{2}}-\frac{0.694}{\left(\frac{\omega}{\omega_{0}}\right)^{4} B^{2}}+\frac{1.389}{\left(\frac{\omega}{\omega_{0}}\right)^{2} B^{2}} \pm \frac{0.694 \sqrt{\left[1-\left(\frac{\omega}{\omega_{0}}\right)^{2}\right]^{4}+2.88\left(\frac{\omega}{\omega_{0}}\right)^{8} B^{2} w_{0}^{2}}}{\left(\frac{\omega}{\omega_{0}}\right)^{4} B^{4}}
$$

Equation (5.21), given the substitution, and equation (5.22) show that the relative motion in this case does not run linearly with respect to the displacement $w_{0}$.

\section{Conclusions}

Both the analysis and Figs. 4 and 6 suggest that it is possible to select parameters of stiffness and damping for linear models of vibration dampers that will provide effective vibration isolation in the analyzed excitation frequency range. A further increase in vibration isolation efficiency can be achieved by introducing materials with nonlinear characteristics as shown in Figs. 7 and 8 .

Energy dissipation increases as the stiffness of the vibration isolation system decreases. Given the above discussion, the following generalized conclusions can be drawn about the efficiency of the vibration isolation system:

a) If $\omega \ll \omega_{0}$, given the excitation force, the amplitude ratio of the force transmitted to the base to the excitation force amplitude is close to one and, similarly, given the kinematic excitation, the ratio of the steady-state vibration amplitude to the excitation amplitude is also close to one, then using vibration dampers is no longer effective.

b) If $\omega \approx \omega_{0}$, the amplitude ratio of the force transmitted to the base to the amplitude of the excitation force increases and reaches significant values at low damping, the spring support should prevent operation in this range, since the forces transmitted by the system may have larger amplitudes than the excitation forces or absolute displacements whose amplitude is larger than the displacement from excitation.

c) If $\omega / \omega_{0}>\sqrt{2}$, the vibration isolation is efficient. The lower the damping, the greater the vibration isolation efficiency. 
d) In the resonance range, the amplification factor $T_{a}$ can be reduced by applying high damping. Therefore, if a machine or device equipped with a hydraulic valve operates for a longer period of time in the resonance range, heavy damping materials should be used in order to prevent excessive vibration amplitudes of the valve body.

The linear and nonlinear mathematical models of vibration isolation discussed in this paper can be used to select appropriate features of materials in terms of the isolation efficiency.

\section{References}

1. Addison A., Vacca A., Cristofori D., 2017, Active vibration damping in hydraulic construction machinery, Procedia Engineering, 176, 514-528

2. Balachandran B., Magrab E.B., 2009, Vibrations, Cengage Learning, Toronto

3. Bocian M., 2019, Selected Methods of Modelling and Identification of Complex Dynamic Systems, Publishing House of the Wrocław University of Science and Technology, Wrocław

4. Bocian M., Kulisiewicz M., 2014, Method of identifying nonlinear characteristic of energy dissipation in dynamic systems with one degree of freedom, Archives of Civil and Mechanical Engineering, 14, 3, 354-359

5. Bogdevičius M., Karpenko M., Bogdevičıus P., 2021, Determination of rheological model coefficients of pipeline composite material layers based on spectrum analysis and optimization, Journal of Theoretical and Applied Mechanics, 59, 2, 265-278

6. Cempel C., 1989, Applied Vibroacoustic, Polish Scientific Publishers, Warszawa

7. Fiebig W., Wróbel J., 2017, Two stage vibration isolation of vibratory shake-out conveyor, Archives of Civil and Mechanical Engineering, 17, 2, 199-204

8. Gao P., Yu T., Zhang Y., Wang J., Zhai J., 2021, Vibration analysis and control technologies of hydraulic pipeline system in aircraft, Chinese Jornal of Aeronautics, 34, 4, 83-114

9. Glanowski G., 2001, Hydraulic proportional control technique, Hydraulics and Pneumatics, 1

10. Goliński J., 1979, Vibration Isolation of Machines and Devices, Scientific Publishing of WNT, Warszawa

11. Guo N., Wang F., Wang L., 2019, Design and analysis of an active-controlled hydraulic low-frequency vibration isolator, Journal of Engineering, 2019, 13, 98-101

12. Harris C.M., Piersol A.G., 2002, Shock and Vibration Handbook, McGraw-Hill, New York

13. IBRAhim R.A., 2008, Recent advances in nonlinear passive vibration isolators, Journal of Sound and Vibration, 314, 371-452

14. Kollek W., Osiński P., Stosiak M., Wilczyński A., Cichoń P., 2014, Problems relating to high-pressure gear micropumps, Archives of Civil and Mechanical Engineering, 14, 1, 88-95

15. Kudźma Z., Stosiak M., 2013, Influence of throttling control methods on the noise of a hydrostatic transmission, Hydraulics and Pneumatics, 33, 1, 21-25

16. Kudźma Z., Stosiak M., Herok S., 2014, Setup for determining static and dynamic characteristics of proportional valves (in Polish), Pomiary Automatyka Robotyka, 18, 3, 112-119

17. Kulisiewicz M., Piesiak S., Bocian M., 2001, Identification of nonlinear damping using energy balance method with random pulse excitation, Journal of Vibration and Control, 7, 5, 699-710

18. MacDuff J.N., Curreri J.R., 1960, Vibrations in Technology, State Technical Publishers, Warszawa

19. Osiecki A., 1998, Hydrostatic Drive of Machines, Scientific Publishing of WNT, Warszawa 
20. Pawlaczyk-Łuszczyńska M., Augustyńska D., Kaczmarska A., 2001, Infrasound noise. Measurement procedure. Documentation of the proposed occupational exposure limit values, Fundamentals and Methods of Work Environment Assessment, XVII, 2(28).

21. Pizoń A., 1995, Electrohydraulic analog and digital automation systems. Scientific publishing of WNT, Warszawa

22. Stosiak M., 2006, The influence of mechanical vibrations of the substrate on pressure pulsation in the hydraulic system, Hydraulics and Pneumatics, 3, 5-8

23. StryczeK S., 2005, Hydrostatic Drive, Scientific Publishing of WNT, Warszawa

24. Tomasiak E., 2001a, Hydraulic and Pneumatic Drives and Controls, Publishing House of the Silesian University of Technology, Gliwice

25. TOMASIAK E., 2001b, Interdiscyplinarity of the proportional control technique, Hydraulics and Pneumatics, 4

Manuscript received April 22, 2021; accepted for print November 8, 2021 